\title{
OUTCOMES OF CIRCUMFERENTIAL V/S ANTERIOR TUCKING TYMPANOPLASTY TECHNIQUE IN INACTIVE MUCOSAL CHRONIC OTITIS MEDIA WITH SUBTOTAL PERFORATIONS: A PROSPECTIVE OBSERVATIONAL STUDY
}

\author{
SULTAN SINGH RULANIA ${ }^{1}$, SUSHMA MAHICH ${ }^{2 *}$, REKHA HARSHVARDHAN ${ }^{3}$ \\ ${ }^{1}$ Department of Otorhinolaryngology, CHC, Achrol, Jaipur, Rajasthan. ${ }^{2}$ Department of Otorhinolaryngology, CHC, Pushkar, Ajmer, \\ Rajasthan. ${ }^{3}$ Department of Otorhinolaryngology, SMS Medical College, Jaipur, Rajasthan. Email: sushmamahich@gmail.com
}

Received: 30 June 2021, Revised and Accepted: 12 August 2021

\section{ABSTRACT}

Objective: The objective of the study is to compare circumferential versus anterior tucking underlay tympanoplasty technique.

Methods: In this prospective observational study, 100 patients with chronic otitis media (Inactive mucosal type) were included, who were randomly allocated in two groups; Group I which comprised of 50 patients in which tympanoplasty with anterior tucking was done, and Group II comprised of 50 patients in which circumferential flap tympanoplasty was done. Improvement in the hearing gain and graft uptake success rate was compared.

Results: The mean air-bone gap (ABG) changed from $28.74 \mathrm{~dB}$ to $11.52 \mathrm{~dB}$ after anterior tucking with a mean change of $17.22 \mathrm{~dB}$ and this change was found to be statistically significant $(\mathrm{p}<0.001)$. Similarly, the mean ABG changed from $28.92 \mathrm{~dB}$ to $11.86 \mathrm{~dB}$ after a circumferential flap with a mean change of $17.06 \mathrm{~dB}$ and this change was also found to be statistically significant $(\mathrm{p}<0.001)$. There was a slightly better improvement $(17.22 \mathrm{~dB})$ in the anterior tucking group as compared to the circumferential flap (17.06 dB). This difference was, however, not found to be statistically significant $(p=0.830)$. Three-month graft uptake rate in the anterior tucking group was found $92 \%$ and in the circumferential group was $94 \%$. ( $>>0.05$ ).

Conclusions: Our study concluded that both techniques have almost the same results with good graft uptake. Results of hearing improvements in both techniques were also comparable.

Keywords: Subtotal perforation, Tympanoplasty, Anterior tucking, Circumferential tympanomeatal flap.

(C) 2021 The Authors. Published by Innovare Academic Sciences Pvt Ltd. This is an open access article under the CC BY license (http://creativecommons.org/ licenses/by/4.0/) DOI: http://dx.doi.org/10.22159/ajpcr.2021v14i10.42707. Journal homepage: https://innovareacademics.in/journals/index.php/ajpcr

\section{INTRODUCTION}

Tympanoplasty is a surgical process that removes the infection from the middle ear, makes it dry, and restores middle ear function in patients with chronic otitis media. Type 1 tympanoplasty (also known as myringoplasty) is limited only to repairing the tympanic membrane (TM) without disturbing ossicles. Several investigations are done regarding the impact of various factors such as perforation size, sex, age, discharge status of the ear at the time of surgery, surgical approaches and techniques, and materials used for the graft.

Robert et al. examined the risk factors of re-perforation following tympanoplasty. They found that surgical technique was the more effective factor in the final results based on statistical analysis. Subtotal perforation involves all four quadrants of pars tensa and reaches up to fibrosis annulus. Due to the acute angle between the TM and the anterior canal wall, the underlay technique is less favorable in subtotal perforation, as it includes lack of graft support and less vascularity, with a greater risk of reperforation [1]. To improve the hearing gain and graft uptake success rate, we used two modifications of the underlay technique, one was anterior tucking tympanoplasty and the second one was circumferential tympanomeatal flap tympanoplasty. Various studies have been conducted to compare these techniques but very few studies are from this region of India [2-4]. Hence, we aimed to compare the success rate of graft uptake and post-operative hearing improvement in circumferential versus anterior tucking underlay tympanoplasty technique in chronic otitis media with an inactive mucosal disease with subtotal perforation.

\section{METHODS}

This hospital-based prospective observational study was conducted for a period of 1 year from December 2017 to November 2018. Total
100 patients with chronic otitis media (inactive mucosal type) were enrolled, who were randomly allocated in two groups; Group 1 which comprised of 50 patients in which tympanoplasty with anterior tucking was done, Group 2 comprised of 50 patients in which circumferential flap tympanoplasty was done. Patients were randomly allotted into two treatment groups using a sealed envelope technique. All the patients underwent tympanoplasty under general anesthesia or local anesthesia through a post-aural approach. This study was approved by the institutional ethical committee. After explaining the treatment options to the subjects in detail, written consent was obtained from those who agreed to participate in the study, and in case of patients below 18 years of age, consent was taken from guardians. The sample size was 47 in each group at $95 \%$ confidence interval and $80 \%$ power to verify the difference of $20 \%$ in graft uptake in both methods (circumferential $96 \%$ vs. anterior tucking $76 \%$ ).

Patients age group between 15 and 45 years diagnosed with chronic otitis media of inactive mucosal type with conductive hearing loss with subtotal perforation who are fit for the tympanoplasty surgery and having no evidence of active infection in the nose and throat were included in the study. Patients with active disease, patients in whom ossicular chain status could not be assessed, patients who required revision tympanoplasty, and patients with tympanosclerosis mixed sensorineural hearing loss, chronic suppurative otitis media atticoantral type, ossicular chain fixation or disruption were excluded out from the study.

\section{Surgical techniques}

Post-auricular Wilde's incision was given. Temporalis graft was harvested. A T-shaped incision in the periosteum overlying the mastoid was given. Periosteum elevated and moved anteriorly into the ear canal. Elevation of the tympanomeatal flap was done to inspect under the 
surface of the TM for squamous epithelium and to inspect the middle ear.

In anterior tucking technique, elevation of the tympanomeatal flap at 12 'o clock to 6' o clock and a small horizontal incision is placed, about $5 \mathrm{~mm}$ lateral to the annulus, anterosuperior and a tunnel is created with the help of a round knife by medially elevating a small cuff of skin along with the annulus (starting at about one o'clock for the right ear and eleven o'clock for the left). The tip of the temporalis graft is pulled out through this tunnel; the graft is made to rest in between the skin cuff and meatal bony wall.

In circumferential tympanomeatal flap technique, posterior canal skin was incised $4 \mathrm{~mm}$ medial to the spine of Henle and tympanomeatal flap elevated along with posterior annulus continued anteriorly from 1'o clock to 4'o clock position. The graft was placed under the handle of the malleus and graft margins lies over the bony canal wall.

Following either of technique, packing of the middle ear and Eustachian tube was done with Gel foam. Replacement of the tympanomeatal flap was done after that. Gel foam placed over the TM remnant, graft and TM flap, after that closure of the post-auricular incision was done and lastly, mastoid dressing was applied.

All patients participating in the study underwent an audiometric assessment for hearing outcome before surgery and at 3 months after surgery. The graft uptake outcome was assessed by otoscopic examination.

Data were collected using case record forms and were entered on a Microsoft Excel spreadsheet. Nominal/categorical variables were summarized as frequency and percentage and were analyzed using the chi-square test/Fisher exact test as applicable. Continuous variables were summarized as mean and standard deviation and were analyzed using an independent sample t-test for comparison between the two groups. For pre and post-operative comparison with the same group, paired sample t-test was used. A p $<0.05$ was taken as statistically significant. All statistical analyses were done using Epi info version 7.2.1.0.

\section{RESULTS}

A total of 100 cases were included in this study, out of which 66 were males and 34 were females with a male-to-female ratio of 1.9:1. Most of the study subjects were below 25 years of age $(68 \%)$ and $17 \%$ were in age group between 26 and 30 years. $8 \%$ of patients were in age group between 31 and 35 years and only 7 were above 35 years. No significant difference was observed between male and female subjects concerning age distribution $(\mathrm{p}=0.984)$ in our study. Most of the male subjects were aged $21-25$ years $(34.8 \%)$ followed by $\leq 20$ years $(31.8 \%)$. Similarly, most of the females were also aged $21-25$ years (35.3\%) and $\leq 20$ years $(35.3 \%)$. No significant difference was observed between male and female subjects concerning age distribution $(\mathrm{p}=0.984)$.

Discharge was the most common symptom in both the anterior tucking group (96\%) as well as the circumferential flap group (86\%) followed by hearing loss. Earache and tinnitus were relatively less common symptoms. No significant difference was seen in the frequency of any symptom between the two groups. After three months of post-operative period, graft uptake rate was $94 \%$ in the circumferential flap group as compared to the anterior tucking group (92\%). Graft uptake failure was seen in $3(6 \%)$ circumferential flap group and $4(8 \%)$ cases in the anterior tucking group (Table 1 ).

The mean air conduction (AC) changed from $38.1 \mathrm{~dB}$ to $21.46 \mathrm{~dB}$ after anterior tucking with a mean change of $16.64 \mathrm{~dB}$ and this change was found to be statistically significant $(\mathrm{p}<0.001)$. Similarly, the mean AC changed from $38.66 \mathrm{~dB}$ to $22.44 \mathrm{~dB}$ after a circumferential flap with a mean change of $16.22 \mathrm{~dB}$ and this change was also found to be statistically significant $(\mathrm{p}<0.001)$. The mean bone conduction
(BC) changed from $9.12 \mathrm{~dB}$ to $9.94 \mathrm{~dB}$ after anterior tucking with a mean change of $0.82 \mathrm{~dB}$ and this change was found to be statistically significant $(\mathrm{p}<0.001)$. Similarly, the mean $B C$ changed from $9.72 \mathrm{~dB}$ to $10.58 \mathrm{~dB}$ after a circumferential flap with a mean change of $0.86 \mathrm{~dB}$ and this change was also found to be statistically significant $(\mathrm{p}<0.001)$.

The mean air-bone gap (ABG) in Fig.1, changed from $28.74 \mathrm{~dB}$ to $11.52 \mathrm{~dB}$ after anterior tucking with a mean change of $17.22 \mathrm{~dB}$ and this change was found to be statistically significant $(\mathrm{p}<0.001)$. Similarly, the mean ABG changed from $28.92 \mathrm{~dB}$ to $11.86 \mathrm{~dB}$ after a circumferential flap with a mean change of $17.06 \mathrm{~dB}$ and this change was also found to be statistically significant $(\mathrm{p}<0.001)$. There was $17.22 \mathrm{~dB}$ improvement in the anterior tucking group as compared to the $17.06 \mathrm{~dB}$ in circumferential flap. This difference was, however, not found to be statistically significant $(\mathrm{p}=0.830)$ as showing in Table 2 (Table 2 and Fig. 1).

Table 3 illustrates that although there was an improvement in ABG in both groups, there was a slightly better improvement $(17.22 \mathrm{~dB})$ in the anterior tucking group as compared to circumferential flap (17.06 dB). This difference was, however, not found to be statistically significant $(\mathrm{p}=0.830)$

\section{DISCUSSION}

Tympanoplasty is the operative procedure performed to repair the TM perforation and to improve hearing level [2]. The graft success rate depends on various factors such as the size of the perforation, functioning of the Eustachian tube, graft placement techniques, and the experience of the operating surgeon. There is marked diversity noted in achieving an intact TM following tympanoplasty [3]. It is often reported that repair of anterior and subtotal perforation by conventional underlay technique is less successful when compared to small perforation because it is technically more difficult [4]. In the study by Lee et al. [5], the success rate for small perforation was $74.1 \%$ and for large anterior and subtotal perforation was $56 \%$, showing that small perforations have a more favorable outcome. Two modified techniques to close subtotal perforations of the TM in chronic otitis media of inactive mucosal type were used to improve the success rates. Circumferential elevation of tympanomeatal over the bony canal and underlay graft placement is thought to a good surgical technique for TM grafting as it ensures elevation of canal skin over the Eustachian

Table 1: Graft uptake rate at three months in both the groups

\begin{tabular}{llll}
\hline Graft uptake & $\begin{array}{l}\text { Anterior tucking } \\
\text { group n (\%) }\end{array}$ & $\begin{array}{l}\text { Circumferential flap } \\
\text { group n (\%) }\end{array}$ & p-value \\
\hline Yes & $46(92 \%)$ & $47(94 \%)$ & 0.999 \\
No & $4(8 \%)$ & $3(6 \%)$ & \\
Total & 50 & 50 & \\
\hline
\end{tabular}

Table 2: Change in ABG (db) after procedure among both the groups

\begin{tabular}{lllll}
\hline Group & Time & Mean \pm SD & $\begin{array}{l}\text { Mean } \\
\text { change }\end{array}$ & p value \\
\hline Anterior & Pre-operative & $28.74 \pm 3.46$ & $17.22 \pm 3.86$ & $<0.001^{*}$ \\
tucking group & Post-operative & $11.52 \pm 4.39$ & & \\
Circumferential & Pre-operative & $28.92 \pm 3.54$ & $17.06 \pm 3.58$ & $<0.001^{*}$ \\
flap group & Post-operative & $11.86 \pm 5.52$ & & \\
\hline *Significant. ABG: & Air-bone gap & & &
\end{tabular}

Table 3: Comparison of change in ABG (db) after both procedures

\begin{tabular}{llll}
\hline Time & $\begin{array}{l}\text { Anterior tucking } \\
\text { group }\end{array}$ & $\begin{array}{l}\text { Circumferential } \\
\text { flap group }\end{array}$ & p-value \\
\hline $\begin{array}{l}\text { Pre-operative- } \\
\text { change in ABG }\end{array}$ & $28.74 \pm 3.46$ & $28.92 \pm 3.54$ & 0.798 \\
Post-operative & $11.52 \pm 4.39$ & $11.86 \pm 5.52$ & 0.734 \\
Change in ABG & $17.22 \pm 3.86$ & $17.06 \pm 3.58$ & 0.830 \\
\hline
\end{tabular}

ABG: Air-bone gap 
tube area for a good assemble between the temporalis graft and the flap to increase its success rate. However, the elevation of the tympanic annulus over the anterior superior quadrant can lead to a serious complication, i.e., blunting of the tympanomeatal angle resulting in conductive hearing loss [6]. Anterior tucking is a technical modification. In this technique, in addition to placing the graft under the remnant of the TM using the underlay technique, a part of the graft is pulled out through a small window created in the skin of the anterior wall of the external auditory canal [7]. The mean age of patients in our study overall was $25.13 \pm 6$ years. Most of the study subjects were below 25 years of age $(68 \%)$ and $17 \%$ were aged $26-30$ years and $8 \%$ of patients were aged $31-35$ years and only 7 were above 35 years. It was similar to the study of Magsi et al. in which patients were aged 5-50 years and had a maximum number of patients aged 11-20 years [8]. Yoon et al. had all the patients aged 15 years or less [9]. In contrast to this study, Rathi et al. study reported slightly lower mean age which might be due to the inclusion criteria where the age range was restricted only between 10 and 60 years [10].

In the present study, most of the male subjects were aged 21-25 years (34.8\%) followed by $\leq 20$ years (31.8\%), similarly, most of the females were also aged $21-25$ years (35.3\%) and $\leq 20$ years $(35.3 \%)$. No significant difference was observed between male and female subjects with age distribution $(\mathrm{p}=0.984)$. In this study, most of the patients in the anterior tucking group were aged $\leq 20$ years $(30 \%)$ followed by $21-$ 25 years $(28 \%)$. Most of the patients in the circumferential flap group were aged $21-25$ years ( $42 \%)$, followed by $\leq 20$ years (36\%). Both the groups were similar in their age composition. Surgeries were more commonly performed on the left side in both the anterior tucking group $(64 \%)$ as well as circumferential flap group (56\%). Both groups were found to be similar with the side of the procedure $(p=0.540)$.

In our study, discharge was the most common symptom in both the anterior tucking group (96\%) and circumferential flap group (86\%) followed by hearing loss. It was the same as the study done by Rathi et al. [10]. Earache and tinnitus were relatively less common symptoms. No significant difference was seen in the frequency of any symptom between the two groups.

The mean AC changed from $38.1 \mathrm{~dB}$ to $21.46 \mathrm{~dB}$ after anterior tucking with a mean change of $16.64 \mathrm{~dB}$ and this change was found to be statistically significant $(\mathrm{p}<0.001)$. Similarly, the mean AC changed from $38.66 \mathrm{~dB}$ to $22.44 \mathrm{~dB}$ after a circumferential flap with a mean change of $16.22 \mathrm{~dB}$ and this change was also found to be statistically significant $(p<0.001)$. Although there was an improvement in AC in both groups, there was a slightly better improvement $(16.64 \mathrm{~dB})$ in the anterior tucking group as compared to the circumferential flap (16.22 dB). This difference was, however, not found to be statistically significant $(\mathrm{p}=0.550)$. The mean BC changed from $9.12 \mathrm{~dB}$ to $9.94 \mathrm{~dB}$ after anterior tucking with a mean change of $0.82 \mathrm{~dB}$ and this change was found to be statistically significant $(\mathrm{p}<0.001)$. Similarly, the mean BC changed from $9.72 \mathrm{~dB}$ to $10.58 \mathrm{~dB}$ after a circumferential flap with a mean change of $0.86 \mathrm{~dB}$ and this change was also found to be statistically significant $(\mathrm{p}<0.001)$. Although there was an improvement in BC in both groups, there was a slightly better improvement $(0.86 \mathrm{~dB})$ in the circumferential flap group as compared to anterior tucking $(0.82 \mathrm{~dB})$. This difference was, however, not found to be statistically significant $(p=0.854)$. The mean ABG changed from $28.74 \mathrm{~dB}$ to $11.52 \mathrm{~dB}$ after anterior tucking with a mean change of $17.22 \mathrm{~dB}$ and this change was found to be statistically significant $(p<0.001)$. Similarly, the mean ABG changed from $28.92 \mathrm{~dB}$ to $11.86 \mathrm{~dB}$ after a circumferential flap with a mean change of $17.06 \mathrm{~dB}$ and this change was also found to be statistically significant $(\mathrm{p}<0.001)$. There was an improvement in $\mathrm{ABG}$ in both group, and there was a slightly better improvement $(17.22 \mathrm{~dB})$ in the anterior tucking group as compared to circumferential flap $(17.06 \mathrm{~dB})$. This difference was, however, not found to be statistically significant $(p=0.830)$.

In Singh et al. study 58 adult patients of both sexes with anterior or subtotal perforations underwent circumferential subannular tympanoplasty [11]. The mean pre-operative ABG was $33.05 \mathrm{~dB}$; the

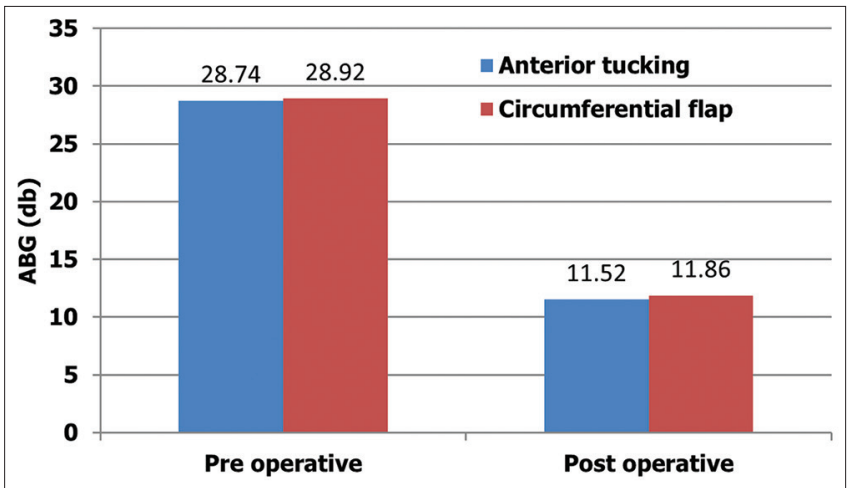

Fig. 1: Comparison of change in air-bone gap (db) after the procedure in both groups

mean post-operative $A B G$ was $18.12 \mathrm{~dB}$, and the mean $\mathrm{ABG}$ closure was $14.69 \mathrm{~dB}$. Thus, there was a significant improvement in hearing $(p=0.002)$; which was comparable to our study results.

In Rastogi et al. study, 40 patients underwent tympanoplasty with tympanomeatal flap elevated all around with 360-degree elevation of the annulus [12]. The average hearing loss in a pre-operative patient was $38.55 \mathrm{~dB}$ which improved to $17.33 \mathrm{~dB}$ in a post-operative patient with improvement by $21.22 \mathrm{~dB}$ at 3 months post-operatively $(\mathrm{p}<0.05)$. These results were also similar to our results.

In Mokhtarinejad et al. study, (Group A) circumferential subannular grafting and 25 cases (Group B) of underlay tympanoplasty with the extension of the anterior edge of the graft forward against the lateral wall of the Eustachian tube and they found success rate in $97 \%$ in group A and $100 \%$ in group B patients, improvement of the $\mathrm{AC}$ thresholds in all frequencies and closure of the mean ABG were significant and similar among two groups; A and in group B patients [13]. The results of the study of Rathi et al. were also comparable to our results. Intercomparison between superiorly based circumferential tympanomeatal flap tympanoplasty (STT) and anterior anchoring flap tympanoplasty (ATT) of the post-operative mean ABG at 6 months postsurgery showed no statistically significant difference.

Various surgeons have used different kinds of grafts to repair TM perforations. The most popular are autogenous grafts. Zollner used a pedicled ear canal skin graft to close perforations [14]. Shea introduced vein graft to close TM perforations [15]. It goes to the credit of Heermann for introducing temporalis fascia as a grafting material in tympanoplasty. We used temporalis fascia graft to close subtotal perforations and could achieve good results both in terms of drum healing (92\%) and closure of (A-B) gap of $17.22 \mathrm{~dB}$ in anterior tucking group and $17.06 \mathrm{~dB}$ in circumferential flap group. The $3-\mathrm{month}$ graft uptake rate in anterior tucking group was $92 \%$ and it was $94 \%$ in circumferential flap group, which when compared with each other showed no statistically significant difference $(p=0.999)$. Graft uptake failure was seen $4(8 \%)$ in anterior tucking group and $3(6 \%)$ in circumferential flap group. Rathi et al. study attained drum healing rate 93.33\% in STT group and $86.67 \%$ in AAT group [10]. Mishra et al. in their study attained drum healing $97 \%$ by doing STT technique which was comparable to our study with 94\% [2]. In Hosamani et al. study, patients with anterior AAT technique showed $95.45 \%$ graft uptake in anterior and subtotal perforations [7]. This was also comparable to our results.

\section{CONCLUSIONS}

Subtotal perforations are more prone to failure after underlay technique due to graft lateralization and anterior blunting. Both circumferential flap elevation technique and anterior tucking group show good graft uptake and better hearing improvement rather than simple underlay 
technique. However, in this study, both techniques showed comparable results.

\section{AUTHORS' CONTRIBUTION}

All the authors contributed to the preparation of the final manuscript.

\section{CONFLICTS OF INTEREST}

None.

\section{FINANCIAL SUPPORT}

Nil.

\section{REFERENCES}

1. Applebaum EL, Deutsch EC. An endoscopic method of tympanic membrane fluorescein angiography. Ann Otol Rhinol Laryngol 1986;95:439-43.

2. Okafor BC. The chronic discharging ear in Nigeria. J Laryngol Otol 1984;98:113-9.

3. Olusesi AD, Opaluwah E, Hassan SB. Subjective and objective outcomes of tympanoplasty surgery at National Hospital Abuja, Nigeria 2005-2009. Eur Arch Otolaryngol 2011;268:367-72.

4. Mishra P, Sonkhya N, Mathur N. Prospective study of 100 cases of underlay tympanoplasty with superiorly based circumferential flap for subtotal perforations. Indian J Otolaryngol Head Neck Surg 2007:59:225-8.

5. Lee P, Kelly G, Mills RP. Does the size of the perforation matter? Clin Otolaryngol Allied Sci 2002;27:331-4.
6. Pradeep P, Abhimanyu A, Priti L. Circumferential elevation of tympanomeatal flap: A novel technique for subtotal and anterior perforation closure. Ann Otolaryngol Rhinol 2015;2:1052

7. Hosamani P, Ananth L, Medikeri SB. Comparative study of efficacy of graft placement with and without anterior tagging in type one tympanoplasty for mucosal-type chronic otitis media. J Laryngol Otol 2012;126:125-30.

8. Magsi PB, Jamro B, Sangi HA. Clinical presentation and outcome of mastoidectomy in chronic suppurative otitis media (CSOM) at a tertiary care hospital, Sukkur, Pakistan. Rawal Med J 2012;37:50-3.

9. Yoon TH, Park SK, Kim JY, Pae KH, Ahn JH. Tympanoplasty, with or without mastoidectomy, is highly effective for treatment of chronic otitis media in children. Acta Otolaryngol Suppl 2007;558:44-8.

10. Rathi A, Gite V, Bhargava S, Shetty NA. Comparative study of superiorly based circumferential tympanomeatal flap tympanoplasty with anteriorly anchoring flap tympanoplasty in large, subtotal, and anterior tympanic membrane central perforations in chronic suppurative otitis media of mucosal type. Int J Otorhinolaryngol Head Neck Surg 2018;4:432-9.

11. Singh B J, Sengupta A, Das SK, Ghosh D, Basak B. A comparative study of different graft materials used in tympanoplasty. Indian J Otolaryngol Head Neck Surg 2009;61:131-4.

12. Rastogi S, Pandit R. Modified technique of underlay myringoplasty. J Otolaryngol ENT Res 2018;10:269-72.

13. Mokhtarinejad F, Barzegar F, Okhovat SA. Surgical and hearing results of the circumferential sub annular grafting technique in tympanoplasty: A randomized clinical study. Am J Otolaryngol 2012;33:75-9.

14. Zollner F. Surgery of malformations of the auditory canal and middle ear. Acta Otolaryngol 1954;44:517-24.

15. Shea JJ Jr. Vein graft closure of eardrum perforations. J Laryngol Otol $1960 ; 74: 358-62$ 